\title{
Subjective Evaluation of Life Satisfaction by community-dwelling Spinal Cord Injury Patients Managed at the University College Hospital, Ibadan
}

Malomo $A O^{1}$, Aminu $K^{2}$, Adeolu $A A^{1}$, Adeleye $A O^{1}$, Balogun $J^{1}$, Badejo $O A^{1}$, Shokunbi $M T^{1}$, Jegede $A S^{2}$

1Department of Neurological Surgery, Institute of Neurosciences, University College Hospital, Ibadan and Department of Surgery, College of Medicine, University of Ibadan, Ibadan, Nigeria

${ }^{2}$ Department of Sociology, Faculty of the Social Sciences, University of Ibadan, Ibadan, Nigeria

Keywords
Life
Satisfaction;
Social Role;
Spinal Cord
Injury;
Subjective
Evaluation;
Nigeria

\section{ABSTRACT}

Background: Life satisfaction in Spinal Cord Injury (SCI) population is influenced by the ability to perform social roles and engage in activities. Investigations on the psychosocial aspects of SCI in Nigeria have concentrated on the objective dimensions, while much has not been documented, qualitatively, on life satisfaction among the SCI survivors in our setting. The research focused on the subjective evaluation of well-being related to social role performance among community-dwelling adults with SCI managed at the University College Hospital Ibadan, Nigeria.

Methods: The study design is descriptive and qualitative data collection was utilized. Seventeen SCI patients who had been discharged home were purposively selected and interviewed via telephone. The domains of life evaluated included sexual life, marital life, and general life satisfaction. These were assessed with an interview guide intended for this purpose. Data were thematically content analysed.

Results: Some participants could return to employment and perform occupational roles. The participants described their life as dissatisfactory. Dissatisfaction was reported with sexual and marital life and social interaction after SCI. Family role performance was likewise dissatisfactory. The participants' dissatisfaction with life post-SCI was largely influenced by their internalization and interpretation of the inability to function in areas of life they perceived important.

Conclusion: The subjective evaluation of life reported by persons living with permanent SCI suggests that they require more support from their families, healthcare providers and the community at large. Additionally, their psychosocial needs deserve constant monitoring by the significant others and healthcare providers in order to provide timely countermeasures.

Correspondence to: Malomo, Adefolarin $\mathrm{O}$ Department of Neurological Surgery, Institute of Neurosciences, University College Hospital, Ibadan E-mail: ademalomo@yahoo.com

\section{INTRODUCTION}

Spinal cord injury (SCI) is an unexpected life event. Its burden is globally spread, although, the reports of SCI incidence point at a regional variation between developed and developing nations. An incidence of 13.1-163.4 per million population was documented in the developed countries compared to $13.0-220.0$ in the less- 
developed countries. ${ }^{1}$ Globally, the incidence of SCI is growing and the number of survivors is steadily rising. ${ }^{1}$ Unfortunately, Nigeria like other countries in the global south, lacks adequate data on SCI epidemiology, thus making intercountry comparison difficult. ${ }^{2}$ The available SCI statistics in Nigeria are specific to health facilities, for instance, an average of 90 cases was reported annually in Ibadan, ${ }^{2}$ whereas in Lagos, 34 cases were recorded yearly. ${ }^{3}$

Globally, the incidence of SCI is steadily rising due to the intensification of human activities. ${ }^{1}$ These activities cut across the population boundaries nonetheless, the intensity is higher among the youths and energetic population groups thus predisposing them to the risks of SCI. The common causes of SCI in our environment are motor vehicle crashes, falls, and violence ${ }^{4}$ and researchers have described its impacts as life-changing. 5 Therefore, the younger the affected individuals, the more the disadvantages experienced due to SCI. The higher the number of survivors, the higher the proportion of the population living with its secondary effects because SCI is characterised by a mixture of biological and psychosocial complications ${ }^{6}$ which often creates opportunities for a life with many uncertainties. ${ }^{7}$

Moreover, the patients' adjustment following the SCI involves actively struggling to deal with their new life in the context of disabilities. Hence, the personal well-being of the SCI patients is described as a by- product of SCI complications and disabilities. ${ }^{8}$ Therefore, discerning the psychosocial consequences of the condition is crucial as the patients are forced into a state of dependency for personal needs including survival and recovery, ${ }^{9}$ owing to the changes in their physical, social, cognitive or emotional functioning. ${ }^{10}$ Researchers have observed that SCI indirectly affects life satisfaction through the inability to perform roles and engage in activities. ${ }^{11}$ This is true for complete SCI which tends to affect the well-being and life satisfaction by drowning or diminishing the resilience of the affected individuals, due to its chronic nature.

Extant studies have similarly confirmed the subjective wellbeing among persons with SCI to be lower than what obtains in the larger population. ${ }^{12,13}$ Even for the same group of individuals, life satisfaction was found to be poorer post-SCI. ${ }^{13}$ Generally, a higher level of life satisfaction has been reported in the SCI population in the developed countries compared to what obtains in the developing countries. ${ }^{14,15}$ This was attributed to cultural differences and traditional beliefs about disability and varying standards of available SCI rehabilitation. ${ }^{15}$ Considering the variations in cultural norms across the world, scholarly understanding of the psychosocial aspects of SCI in our environment is expedient and imperatively necessary.

The need for this was supported by literature as investigations on the psychosocial aspects of SCI in Nigeria were 
questionnaire-based and have for the most part focused on the objective dimensions of life satisfaction. ${ }^{16}$ Not much has been documented, qualitatively, on life satisfaction among the SCI survivors in the country. This study, therefore, focused on the identified knowledge gap with the recognition that patients' lives and stories vary depending on the events taking place in their personal and social life. The study assessed life satisfaction among the community-dwelling adults living with complete/permanent SCI. The subjective approach was utilized for this purpose since the patients' accounts are fruitful sources for understanding their experiences.

\section{METHODOLOGY}

The research adopted a descriptive design and a qualitative data collection method. The interview lasted for five weeks [March to April 2018]. Heretofore, no behavioural investigation was conducted on the SCI patients managed at the Neurosurgery Department of the University College Hospital (UCH), Ibadan, the study setting. The Department is staffed by six consultant neurosurgeons and 77 nurses. It is also equipped with 47 adult and 14 paediatric beds. It pioneered the neurosurgery care in the country and boasts of state of the art facilities for managing neurological trauma. The Department is also a major referral centre for SCI care in south-west Nigeria with an average of $90 \mathrm{SCI}$ cases per year. ${ }^{2}$ It runs three specialty clinics including the spine clinic which runs once a week.
All the patients who were treated for spinal cord trauma at the study site constituted the study population. Given the interpretive nature of the study, all the participants were purposively sampled. The inclusion criteria include sustaining the injury as an adult, complete spinal cord injury, willingness to participate in the interview, being an outpatient for a minimum of one year after acute medical intervention following SCI and having a traumatic SCI. The criteria for exclusion are: having a non-traumatic SCI, having received acute care in a different healthcare facility, and presenting with a head injury in addition to SCI.

In-depth interview, a qualitative method of data collection was utilized because this approach is the best for gaining insights, meanings, and interpretations of life satisfaction from the patients' worldview. Individual interviews were conducted with seventeen [17] adults living with complete SCI. The interview was aided by an interview guide designed by the authors. The interview guide was translated into Yoruba language, the local dialect in the study area. Therefore, the interviews were conducted in two languages, English and Yoruba languages, depending on the participants' choice. The translation was done by a Yoruba linguist.

The interview guide comprised prompt questions on demographic background, general life satisfaction and satisfaction with other aspects of life including sexual, marital, reproductive, religious and social life satisfaction. Satisfaction with family role 


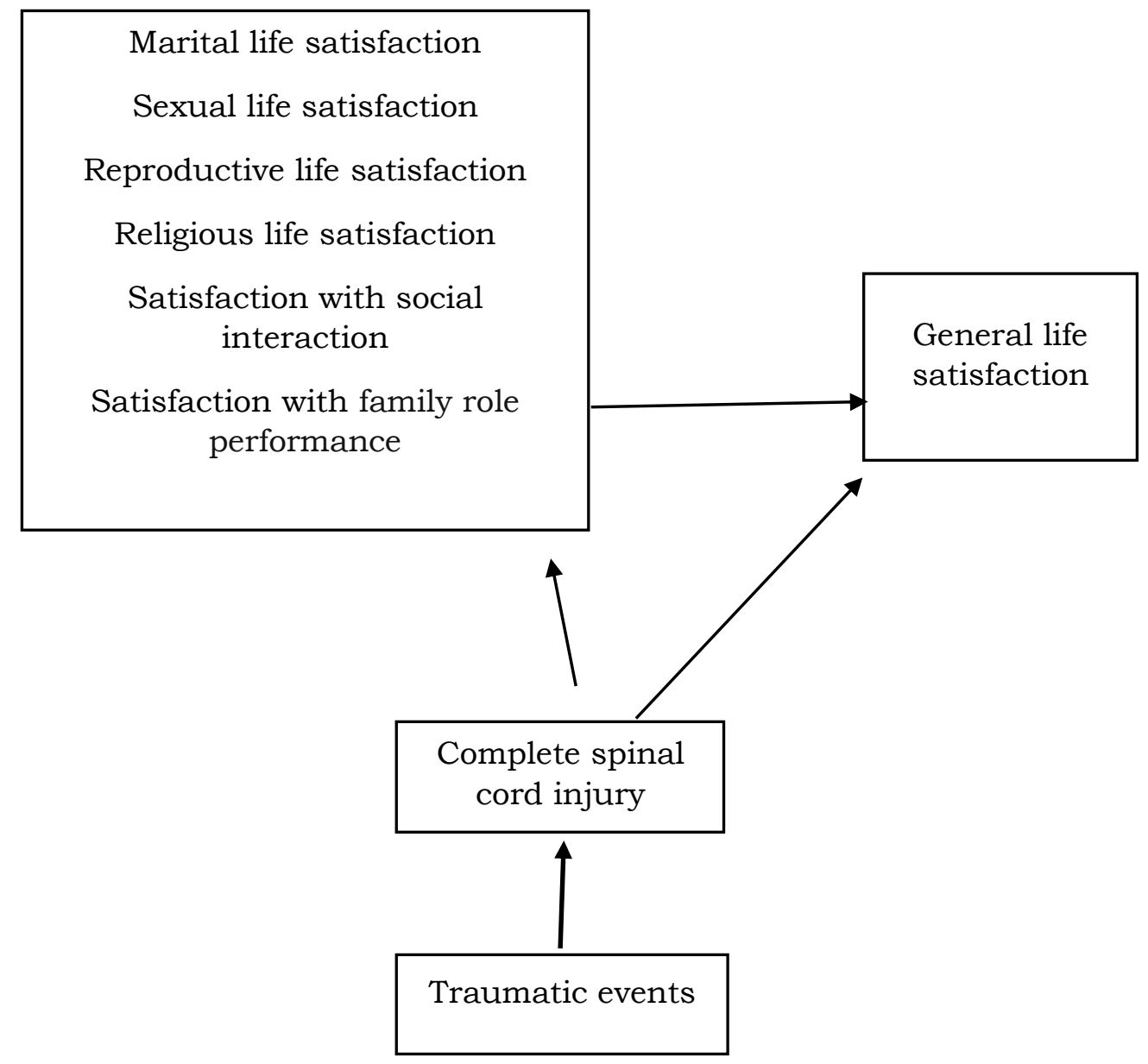

Figure 1: Problem analysis tree on subjective evaluation of life domains post-SCI

performance was equally assessed. These domains of life satisfaction were adapted from Frisch's work on quality of life. ${ }^{17}$ The interest in these domains is because only the areas of life perceived as important and goal-relevant have been found to impact life satisfaction. ${ }^{17}$ These assessments, therefore, targeted areas of life deemed important amongst Africans and most likely to be affected by a permanent disability. Locating the participants outside the hospital setting was difficult because the majority were residents outside Ibadan, as a result, they were all contacted and interviewed over the phone for the convenience of the investigators and the participants.

Transcribed data were coded with the Atlas.ti software. The codes were grouped into code families. This simplified the grouping of related codes into themes which were subsequently analysed. The major and recurring themes were content analysed and presented in a problem analysis tree as shown in Figure 1 below. The result presentation was equally done via verbatim quotation for easy interpretation. The study constituted no harm to the participants and all ethical protocols were strictly adhered to. Confidentiality and anonymity of 
interviewees were ensured especially because the study adopted telephone interviews. In addition, the participants gave verbal informed consent after the consent statements were read to them. The data collection, transcription, coding and analysis were done by the investigators. No other person had access to the information. The institutional ethical review board ratified the study, the approval number is NHREC/05/01/2008a.

\section{RESULTS}

\section{Participants' background information:}

The participants' social and demographic information indicates that their ages ranged from 31 to 59 years. The majority [10] were males while seven [7] were females. All the participants were economically engaged and had sources of income before the injury, while one was an apprentice. More than half [n=9] of the participants had returned to employment post-hospital discharge. Their occupations include agricultural production, teaching, trading, fashion designing, and manufacturing. Further information on their background is shown in Table 1. The findings on the different domains assessed are presented next.

Satisfaction with Marital Life: For the marital life domain, the study found that most participants were dissatisfied. The finding further reveals some variations along the gender line as all the participants who were dissatisfied with their marital relationship happened to be men while those who were averagely satisfied with this domain were women.
"I am satisfied because my wife is standing by me" (Male/52 years/IDI 13)

Furthermore, some of the participants who were never married expressed dissatisfaction with their marital status blaming it on the injury. One of the participants in this category expressed himself thus: "Won o fe wa o, won $n$ sa fun wa nitori 'pe a wa l'ori wheelchair".

Translation: "They have refused to marry me, they are avoiding me because they see me in the wheelchair". (Male/35 years/IDI 9)

Another participant who was engaged before the injury also noted that his fiancé ran away after he sustained the injury.

"I am not satisfied because since my fiancé left me I have been trying to get another lady without luck..." (Male/41 years/IDI 5)

A participant who was previously married narrated his experience as shown below:

"I am not satisfied at all because I am divorced...I do feel like having a woman by my side but because of my condition, it breaks my heart most times..." (Male/31 years/IDI 4).

The participant blamed his dissatisfaction with his marital life on the challenges he had in his marriage which led to the dissolution of the union. He also expressed emotional anguish due to the difficulties he encountered in getting another partner. Satisfaction with Sexual Life: The findings on the sexual life revealed that most of the participants were not satisfied with their 
Table 1: Socio-demographic characteristics of the participants

\begin{tabular}{|c|c|c|}
\hline Characteristics & Frequency $(n=17)$ & Percent \\
\hline \multicolumn{3}{|l|}{ Age (years) } \\
\hline $30-34$ & 6 & 35.3 \\
\hline $35-39$ & 3 & 17.6 \\
\hline $40-44$ & 4 & 23.5 \\
\hline $45-49$ & 1 & 5.9 \\
\hline $50-54$ & 1 & 5.9 \\
\hline $55-59$ & 2 & 11.8 \\
\hline \multicolumn{3}{|l|}{ Sex } \\
\hline Male & 10 & 58.8 \\
\hline Female & 7 & 41.2 \\
\hline \multicolumn{3}{|l|}{ Ethnicity } \\
\hline Yoruba & 16 & 94.1 \\
\hline Igbo & 1 & 5.9 \\
\hline \multicolumn{3}{|l|}{ Education } \\
\hline Primary & 1 & 5.9 \\
\hline Secondary & 6 & 35.2 \\
\hline Post-Secondary & 9 & 53.0 \\
\hline No response & 1 & 5.9 \\
\hline \multicolumn{3}{|l|}{ Marital status } \\
\hline Married & 11 & 64.7 \\
\hline Single & 4 & 23.5 \\
\hline Separated & 1 & 5.9 \\
\hline Widowed & 1 & 5.9 \\
\hline \multicolumn{3}{|l|}{ Religion } \\
\hline Islam & 3 & 17.6 \\
\hline Christianity & 14 & 82.4 \\
\hline \multicolumn{3}{|c|}{ Employment status before SCI } \\
\hline Employed & 15 & 88.2 \\
\hline Unemployed & 2 & 11.8 \\
\hline \multicolumn{3}{|c|}{ Employment status after SCI } \\
\hline Employed & 9 & 52.9 \\
\hline Unemployed & 8 & 47.1 \\
\hline \multicolumn{3}{|c|}{ Current income level (N) } \\
\hline$<30000$ & 3 & 17.6 \\
\hline $31,000-100,000$ & 1 & 5.9 \\
\hline $101,000-200,000$ & 1 & 5.9 \\
\hline Not stable & 12 & 70.6 \\
\hline
\end{tabular}

sexual life. Only one of the participants indicated satisfaction with her sexual life. The dissenting voice below was one of the two females who also expressed satisfaction with their marital lives.

"(Chuckling) we are trying our best. We do have sex". (Female/33 years/IDI 7)
An important finding is that more than onethird of the participants were yet to attempt sexual intercourse with their partners since the time of their discharge from the hospital. This becomes evident here:

"It's not pleasing that one cannot have sex with his wife once in a while but I thank God. 
There is no opportunity for sexual intercourse...” (Male/34 years/IDI 3)

One of the participants revealed why she was yet to try sexual intercourse with her husband.

"Nothing oh...I am unhappy, not able to have sex with my husband. I am not happy about it. I am worried because of my condition (spinal cord injury). I fear that something may go wrong while doing it even before my husband travelled. It is because of fear; that fear is always in me." (Female/42 years/IDI 2)

By fear, she meant she was afraid her injury may be complicated if she engaged in any activity like sex. Another factor preventing some of the interviewees from engaging in sexual intercourse was pressure ulcers. This was cited by some of the interviewees as the reason for their avoidance of sexual intercourse.

"...There is no room for sexual intercourse because I still have some wounds I am nursing so there is no power to have sex. Though I do have erection, I cannot have sex until the wounds heal completely" (Male/34 years/IDI 3)

Despite regaining erection after the injury, the interviewee said he had not engaged in sexual intercourse with his partner due to the pressure ulcers. An interviewee who was averagely satisfied with this life domain further signified that his sexual life satisfaction depended on his wife's disposition. "...at times when I feel happy and wish to do it (have sex), she may refuse. When she is happy she may allow me and when she is not happy I accept it. When she is happy we may have sex like once in three months." (Male/56 years/IDI 1)

Reproductive concerns: Most of the married participants did not have any reproductive concerns, however, they were most worried about their personal and families' well-being. Only one woman indicated that her husband was anxious to see her have another baby. As some participants indicated, their major concern was how to parent and cater to their kids.

"...There's nothing to be worried about since we are not trying to have another baby we have kids already and we stopped having kids before the incident. The one (sexual intercourse) we are doing is for pleasure." (Male/56 years/IDI 1)

\section{Satisfaction with Family Role Performance: On their family role} performance, most interviewees were dissatisfied with their inability to perform their expected roles in the family such as looking after their loved ones, doing house chores, paying children school fees and enforcing child discipline. Some were, however, satisfied with their family role performance, while only a few were averagely satisfied as reflected below:

"Things have changed...I am not satisfied with the way things are, I can no longer perform all my roles like caring for my family but I just thank God that I am not much of a burden to them. I am not also pleased with 
the way things are, having to beg someone to pay my children's school fees but I thank God for that." (Male/34 years/IDI 3)

The inability of the participant to perform all his social roles the way he used to in addition to his loss of independence had a significant effect on his subjective wellbeing.

"The way I am now I am not satisfied because I cannot perform my roles I only try my best. If my wife is busy and the kids need help with their school work I cannot do all those things. As a human being, I am not satisfied I still pray that God should help me to perform my roles.” (Male/42 years/IDI 8)

It was observed that while most of the male participants were worried about their inability to provide for their families, women on their part were not concerned about this. A female interviewee said:

"I thank God for that...I wash the plates; my responsibilities are still there for me. I go to the market myself... I only have a house help who assists me in the kitchen." (Female/42 years/IDI 2)

Satisfaction with Social Interaction: The study found no difference in the number of participants who expressed satisfaction and those who were dissatisfied with the level of their social interaction. Almost half of the participants were satisfied with their social interaction while the same proportion reported dissatisfaction. However, other participants, less than one-fifth, were averagely satisfied as given below:

"You know I have accepted what happened to me as my destiny I cannot blame anybody or transfer aggression and when I relate with them (others) joyfully they also become more cheerful since I am not begging to survive. I have my job and accept what God has done, whatever comes we manage it in the family. That does not allow anybody to misbehave." (Male/56 years/IDI 1)

The participant's assessment of this domain of life satisfaction was due to his ability to actively partake in social interaction with others, especially his friends and loved ones.

"I am satisfied with the interaction I have with them (friends) because most of them are so pleasant and kind to me" (Male/31 years/IDI 4)

The participant above indicated that the people in his network had a friendly disposition towards him hence his satisfaction. On the contrary, the experience of the participant presented next is different.

"I will describe it as dissatisfactory because some people will look at you like someone who was born handicapped not realizing that anybody could be in this situation..." (Male/41 years/ IDI 5)

The above response depicts the interviewee's encounter in his social environment. He noted that people tend to perceive him with disdain due to his disability.

Satisfaction with Religious Life: The majority of the participants were discontent with their religious life while some were satisfied with their religious life post-SCI.

"I am highly satisfied because I have people around who help." (Male/31 years/IDI 4) 
The participant quoted above was satisfied with his religious life because he could perform his religious obligations by courtesy of the support of people who assisted him in getting to the worship centre. However, some dissatisfied interviewees expressed displeasure with their inability to get help whenever they desired to commute to religious centres to worship and fulfil their religious obligations.

"I pray at home I have not been going to church like before the injury..." (Male/32 years/IDI 14)

Since the narratives showed that satisfaction with religious life was dependent on the extent of religious participation, the interviewees were asked to compare this before and after SCI. Most interviewees indicated that their level of religious participation before SCI was comparatively higher while others described it as lower.

"The Bible says in all situation we should praise God. Before, I was a worker in the church and every day once it is 6 p.m. I am already in the church. But now, for 5 months I may not go to church because of transportation challenges and at times because of pains...My attendance at church has reduced but I still give all glory to God." (Male/41 years/IDI 5)

He explained how his participation in religious activities was negatively affected by the injury. Furthermore, the interviewees were similarly asked to assess their level of spirituality before and after SCI. All the participants but one recounted that their level of spirituality increased after the injury.

"I have not lost hope at all. After the injury occurred, I am closer to God...my relationship with God is better and He provides for all my needs promptly." (Male/42 years/IDI 8)

The dissenting voice noted that she was not as close to God as before the injury. To further fathom the reason for the dissatisfaction with religious life, the interviewees were asked to discuss any challenges they had in practising their religion. Only a few did not have challenges with their religious practice however, more than two-third noted that they did encounter challenges in practising their religion. These challenges were grouped into two namely: the problem of accessibility of worship centres and limitation due to bodily functions.

"There are challenges because I cannot go to the mosque like before, I have been praying on the bed. I am not satisfied because of that." (Male/52 years/IDI 13)

The participant found it difficult to access the worship centre. His view depicts that being able to worship in the religious centre is in itself a fulfilling experience, however, this was difficult for him because of SCI hence, the dissatisfaction.

"...For church service, I may not be able to cope with prolonged service. At times I feel somehow and it has been difficult as God has not answered my prayer and it's like I am looking for a miracle." (Female/35 years/IDI 9) 
Her major problem like others in this category was the limitations in bodily functions which made it difficult for her to withstand the long hours of worship.

Satisfaction with Life: Most of the participants were dissatisfied with their lives post-SCI when they assessed and rated their life satisfaction. Only two (2) interviewees expressed satisfaction with their lives while some rated their life satisfaction as average.

"I am satisfied, at least I am grateful to God. I am grateful to Jesus that I am alive up till this moment. I thought my life was hopeless before but now since I went to UCH...I realised there is still hope for me." (Female/59 years/IDI 17)

The interviewee above revealed that she was satisfied with life and thankful because of the psychosocial rehabilitation and interventions she received at the study site. However, few participants dissented, they responded in some ambiguous tone, saying: "thank God". This shows how spiritual the participants are while their responses concealed the true rating of their life satisfaction. The next response is from a dissatisfied interviewee.

"I am not satisfied because it (SCI) has delayed my progress." (Female/33 years/IDI 7)

The interviewee went as far as stating the reason for her dissatisfaction with life. Her response showed that the condition had stalled her life aspirations, hence her dissatisfaction. Another participant noted that:

"The Bible says in everything we should thank God because if I am not alive there is nothing I can do, but with life there is hope. I still pray for improvement." (Female/34 years/IDI 6)

The next narrative captures a different reason for the subjective wellbeing.

“...The state I am now I don't want to be an ingrate because I appreciate what God has done for me. But if I look at it as a human being no one would be happy in this kind of condition." (Male/42 years/IDI 8)

\section{DISCUSSION}

The study assessed the subjective evaluation of well-being among the SCI survivors. The age of the participants in this study ranged from 31 to 59 years while the majority of the participants were aged 31-45 years. This supports the report of another study in Nigeria showing that most victims of SCI are youths. ${ }^{3}$ The age distribution has implications for their physical and mental health because all the participants had irreversible SCI. Moreover, sustaining SCI at this age has consequences on the survivors' economic participation because they are in the working age group. Furthermore, the youths constitute the major asset for driving economic growth therefore, SCI among this population will impact societal development. ${ }^{18}$ The gender distribution in this study confirms the previous findings and available information on SCI epidemiology. It is widely claimed that SCI disproportionately affects 
males more than females. ${ }^{19,20}$ The prevalence among the menfolk is because they traditionally take on physically strenuous jobs and they are more exposed to dangerous activities and violence which put them at more risk than women. Given men's role and status in African societies, several socio-cultural issues are entwined with this such as power and authority dynamics in the family. The majority of the participants were married. This can be attributed to the participants' age distribution; the youngest was 31 years old. The societal pressure on individuals who are unmarried at this age was evident in the study. The desire to get married was expressed by some participants who were not pleased with their marital status which was attributed to SCI. This is similar to the assertions by some researchers that people living with disabilities in Nigeria encounter social stigma, exploitation, and even discrimination. ${ }^{21}$

The study, likewise, found some cases of divorce and separation after the injury, hence, supports the report that separation and divorce are common after SCI. ${ }^{22}$ This may be explained by the perceived burden of care-giving and the fact that people with a disability tend to be dependent on others for their survival. They may also find it difficult to perform the culturally assigned roles and obligations within the family.

More than half of the participants had returned to work after the injury. This level of re-employment post-SCI may be explained with the psychosocial rehabilitation which SCI patients managed at the study site undergo. The finding proves the efficiency of the Holistic Ward Round (HWR) at the Neurosurgery Unit in $\mathrm{UCH}$, Ibadan in restoring patients' and their families' hope. The HWR is a multidisciplinary ward round where all healthcare providers interact with the patients and their family caregivers to review their cases and prepare them for the new life outside the hospital. ${ }^{23}$ One of the objectives of the HWR is to minimize social complications post-hospitalization and to make patients' lives meaningful irrespective of their injuries. ${ }^{23}$ This is done by allaying the fears of the patients and their family caregivers who are made to undergo psychosocial rehabilitation in preparation for the patient's discharge. Details have been documented elsewhere. 23

Notwithstanding the rate of economic participation reported, most of the participants had financial challenges. Other researchers likewise reported financial difficulties in the SCI population. ${ }^{24}$ Financial constraints may have direct and/or indirect effects on the wellbeing of the affected individuals and their immediate families. For instance, they may find it hard to meet their most pressing needs like feeding, medications, hospital follow-up, and physical therapy among other needs. All of which may predispose them to risks of SCI complications such as psychological problems and lowering of their life expectancy. 
It was observed that the participants were dissatisfied with their lives after SCI. This finding agrees with that of a study in the Netherlands. ${ }^{25}$ Life satisfaction encompasses different aspects of life in general. Major factors found responsible for the dissatisfaction with life in the SCI population include the injury complications that affect the different aspects of life like social and family relationships, education, employment, and financial status. ${ }^{26}$ This is because many participants were equally unpleased with other aspects of life assessed in this study. These domains are seemingly very important to the participants and significant to their subjective wellbeing. The dissatisfaction with general life may have consequences on their mental wellbeing, it could lead to psychosocial complications like depression and a higher risk of suicide.

Furthermore, the satisfaction with sexual life was also low within the group. Similar studies support this finding on the sexual domain of life satisfaction. ${ }^{25,27,28}$ This could be attributed to the fact that SCI impairs sexual functioning of survivors, ${ }^{29}$ especially men who depending on the severity of SCI, suffer sexual dysfunctions particularly erectile and ejaculation problems. ${ }^{30}$ Whereas satisfaction with sexual life is central to human identity and it has great effects on human feelings about self, it determines the extent of life satisfaction. ${ }^{31}$ For men, challenges in achieving fulfilment in sexual life is a major emotional burden that has implications on their ego, their person as well as their self-esteem.
Marriage has been identified as a buffer after SCI due to the availability of social support and the emotional benefits of staying married. It was also linked to a better quality of life and life satisfaction in the SCI population. ${ }^{32}$ The study found many participants dissatisfied with this domain however, gender was found to have influenced the subjective evaluation of marital life satisfaction. Additionally, some association was detected between the subjective evaluation of marital life and satisfaction with social role performance and sexual life satisfaction. Perhaps some other factors not revealed by the participants also played a role. Therefore, a study focused on the predictors of marital life satisfaction may further clarify this in the future.

Moving on, most of the married participants did not have any reproductive concerns mainly because they were already parents before the injury. Their main concern was raising the children and providing for their needs. Judging by the importance placed on the number of children in Africa, it is appropriate to say that the participants' disinterest in childbearing was due to the financial and other burdens of SCI on the family including sexual dysfunctions. Being an unplanned life event, SCI may have affected their reproductive choices and subverted their life choices/decisions.

Furthermore, the study found that the participants were not satisfied with their family role performance mostly due to financial constraints and loss of 
independence. It has been consistently reported that SCI survivors are financially insecure whereas most family obligations require finance (such as paying school fees, rent and feeding the family). ${ }^{33}$ Financial constraints may drive the affected families and individuals into poverty given the high cost of SCI care. It may also reduce their life chances and quality of life. Besides, the incapability to live an independent life has implications on the personal fulfilments derived from the ability to execute tasks and perform social roles, these are sufficient to negatively upset the subjective well-being of the concerned individuals.

The satisfaction with social interaction indicated that SCI did affect this domain in the study population; this is contrary to what other studies in the Netherlands discovered.25,34 The reintegration of victims into the community is said to be influenced by SCI especially when physical health problems like pressure ulcers and incontinence which disrupt normal life activities and social well-being are present. ${ }^{35}$ In this study, the proportion of interviewees who were satisfied with their social participation was lower compared to those who were totally dissatisfied and averagely satisfied with their fulfilment of this social obligation. This indicates that SCI hindered these obligations which are important in the African social context. The low level of satisfaction with these domains has implications for their psychosocial wellbeing and quality of life.
Interestingly, many participants were satisfied with their religious lives while their level of spirituality increased after the injury indicating that the patients used religion as a coping strategy following SCI. Many authors have observed that patients and their families use religion to cope with chronic health problems. ${ }^{36}$ Notwithstanding this finding, difficulty or ease in practising religion determined the extent of religious life satisfaction among the participants. Those who found it possible to access worship centres and with little or no health complications aside from the SCI were highly satisfied with this aspect of their lives. Though those who encountered these difficulties were not satisfied, the reasons identified by some participants for their dissatisfaction included limitations in bodily functions, problems of transportation and accessibility challenges. This was likewise observed among the SCI patients in Switzerland. ${ }^{37}$ These challenges hindered the participants' ability to practice their religion hence, their dissatisfaction. The satisfaction with religious life is one of the domains for measuring life satisfaction because of the belief that religious individuals are happier and more satisfied with their lives than non-religious people. 38 The study was constrained by the mode of interview (telephone) adopted in the study as additional cues like facial expressions and body languages which may have helped the data interpretation could not be observed.

In conclusion, the study has shown the social complications associated with SCI in 
the study group. The victims are dissatisfied with life in general and some specific domains of life. Their dissatisfaction resulted from their interpretation and meaning-making around their inability to function in the areas of life they considered important. The dissatisfaction also showed their need for more support from their families, healthcare providers and the community at large. Such support should be individual-specific since human needs, values and life aspirations differ. Besides, their rehabilitation should be further expanded while the SCI survivors should be deeply involved in the rehabilitation process and not reduced to mere recipients of the services. The concern of the healthcare providers should not only be the medical needs, equally important are the psychosocial problems which these people encounter daily. Therefore, the healthcare professionals should endeavour to take into consideration the subjective well-being of their patients since this is essential to the patients' overall health outcome. Hopefully, this will enhance their adjustment to the new life and the inevitable changes in personal life.

Acknowledgements: The investigators are thankful for Mrs V. Ajayi who facilitated the interviews and all the patients who volunteered to share their stories.

\section{REFERENCES}

1. Kang Y, Ding H, Zhou H, Wei Z, Liu L, Pan D, et al. Epidemiology of worldwide spinal cord injury: a literature review [Internet]. Journal of Neurorestoratology, 2017; [cited 2020 Mar 3]. Available from:

https://www.dovepress.com/epidemiology-of- worldwide-spinal-cord-injury-a-literaturereview-peer-reviewed-fulltext-article-JN

2. Malomo AO, Emejulu JK, Odukogbe AA, Shokunbi WA, Shokunbi MT. Cervical spine cord injury in pregnancy. Conservative management of 3 consecutive cases in Ibadan, Nigeria. African Journal of Neurological Sciences. 2006; 25(2): 612

3. Obalum DC, Giwa SO, Adekoya-Cole TO, Enweluzo GO. Profile of spinal injuries in Lagos, Nigeria. Spinal Cord. 2009 Feb; 47(2): 134-137.

4. Nwankwo OE, Uche EO. Epidemiological and treatment profiles of spinal cord injury in southeast Nigeria. Spinal Cord. 2013 Jun; 51(6): 448-452.

5. Ibikunle PO, Okoro EO. A Fifteen Years Retrospective Study of Spinal Cord Injury in South-Eastern Nigeria. Eastern Nigeria. 2018; 17.

6. Kennedy P, Hasson L. The relationship between pain and mood following spinal cord injury. The Journal of Spinal Cord Medicine. 2017; 40(3): 275-279.

7. Yoshida K. Uncertainty in the lives of people with spinal cord injury and rheumatoid arthritis. Canadian Journal of Rehabilitation. 1996; 10(1): 5-14.

8. Van Middendorp JJ, Allison HC, Ahuja S, Bracher D, Dyson C, Fairbank J, et al. Top ten research priorities for spinal cord injury: the methodology and results of a British priority setting partnership. Spinal Cord. 2016; 54(5): 341-346.

9. Angel S. Vulnerable, but strong: The spinal cord-injured patient during rehabilitation. International Journal of Qualitative Studies on Health and Well-being. 2010 Jan 1; 5(3): 5145.

10. Hicken BL, Putzke JD, Novack T, Sherer M, Richards JS. Life satisfaction following spinal cord and traumatic brain injury: A comparative study. Journal of Rehabilitation Research and Development. 2002; 39(3): 359-366.

11. Dijkers, M. Quality of life of individuals with spinal cord injury: a review of conceptualization, measurement, and research findings. Journal of Rehabilitation Research and Development. 2005; 42(3): 87. 
12. Dijkers MPJM. Correlates of life satisfaction among persons with spinal cord injury. Archives of Physical Medicine and Rehabilitation. 1999; 80(8): 867-876.

13. Post MWM, Van Leeuwen CMC. Psychosocial issues in spinal cord injury: a review. Spinal Cord. 2012; 50(5): 382-389.

14. Geyh S, Ballert C, Sinnott A, Charlifue S, Catz A, Greve JD, et al. Quality of life after spinal cord injury: a comparison across six countries. Spinal Cord. 2013; 51(4): 322-326.

15. Songhuai L, Olver L, Jianjun L, Kennedy $\mathrm{P}$, Genlin L, Duff J, et al. A comparative review of life satisfaction, quality of life and mood between Chinese and British people with tetraplegia. Spinal Cord. 2009; 47(1): 82-86.

16. Ekechukwu END, Ikrechero JO, Ezeukwu AO, Egwuonwu AV, Umar L, Badaru UM. Determinants of quality of life among community-dwelling persons with spinal cord injury: A path analysis. Nigerian Journal of Clinical Practice. 2017; 20(2): 163-169.

17. Frisch MB. Quality of Life Assessment/Intervention and the Quality of Life Inventory TM (QOLI $\left.{ }^{\circledR}\right)$. In: The use of psychological testing for treatment planning and outcomes assessment, 2nd ed. Mahwah, NJ, US: Lawrence Erlbaum Associates Publishers; 1999: 1277-1331.

18. Buheji M, Ahmed D. investigating the importance of "youth economy." International Journal of Current Advanced Research. 2017 Mar 1; (6): 2405-2410.

19. Kang Y, Ding H, Zhou H, Wei Z, Liu L, Pan $D$, et al. Epidemiology of worldwide spinal cord injury: a literature review [Internet]. Journal of Neurorestoratology. 2017 [cited 2020 Mar 3]. Available from:

https://www.dovepress.com/epidemiology-ofworldwide-spinal-cord-injury-a-literaturereview-peer-reviewed-fulltext-article-JN

20. World Health Organization. Spinal cord injury [Internet]. 2013 [cited 2020 Mar 3]. Available from: https://www.who.int/newsroom/fact-sheets/detail/spinal-cord-injury

21. Nigerian Institute of Legal Studies. Roundtable On The Unserved Handicapped: Raising Respect And Awareness For The Rights
Of The Disabled In Nigeria 28th June 2010. 2010 [cited 2020 Mar 3]. Available from: https://nials.edu.ng/index.php/2015-12-1016-05-04/roundtables / 147-roundtable-on-theunserved-handicapped-raising-respect-andawareness-for-the-rights-of-the-disabled-innigeria-28th-june-2010

22. Angel S, Buus N. The experience being a partner to a spinal cord injured person: a phenomenological-hermeneutic study. International Journal of Qualitative Studies on Health and Well-Being. 2011; 6(4): 7199.

23. Malomo AO, Aminu K, Adeolu AA, Adeleye AO, Balogun JA, Badejo OA, et al. Assessment of the Holistic Model of Neurosurgical Patient Care at the University College Hospital (UCH), Ibadan. West Afr J Med. 2019 Aug; 36(2): 138-143.

24. Kagawa-Singer M, Blackhall LJ. Negotiating Cross-Cultural Issues at the End of Life: "You Got to Go Where He Lives." JAMA. 2001 Dec 19; 286(23): 2993.

25. van Koppenhagen $\mathrm{CF}$, Post $\mathrm{MW}$, van der Woude LH, de Witte LP, van Asbeck FW, de Groot $\mathrm{S}$, et al. Changes and determinants of life satisfaction after spinal cord injury: a cohort study in the Netherlands. Archives of Physical Medicine and Rehabilitation. 2008; 89(9): 17331740 .

26. Khazaeipour Z, Norouzi-Javidan A, Kaveh M, Khanzadeh Mehrabani F, Kazazi E, EmamiRazavi S-H. Psychosocial outcomes following spinal cord injury in Iran. The Journal of Spinal Cord Medicine. 2014; 37(3): 338-345.

27. Cardoso FL, Porto IP, Carvalho HPD, Ferrari EP. Factors associated with sexual satisfaction of men with spinal cord injury. Fisioterapia e Pesquisa. 2018; 25(1): 35-42.

28. Post MW, Van AD, Van FA, Schrijvers AJ. Life satisfaction of persons with spinal cord injury compared to a population group. Scandinavian Journal of Rehabilitation Medicine. 1998; 30(1): 23-30.

29. Singh R, Rohilla RK, Siwach R, Dhankar SS, Kaur K. Understanding psycho-social issues in persons with spinal cord injury and impact of remedial measures. International Journal of Psychosocial Rehabilitation 2012; 16(1): 95-100. 
30. Hess MJ, Hough S. Impact of spinal cord injury on sexuality: Broad-based clinical practice intervention and practical application. J Spinal Cord Med. 2012 Jul; 35(4): 212-219.

31. Kurpisz J, Mak M, Lew-Starowicz M, Nowosielski K, Bieńkowski P, Kowalczyk R, et al. Personality traits, gender roles and sexual behaviours of young adult males. Annals of General Psychiatry. 2016; 15(1): 28.

32. Khoi EM, Latifi S, Rahdari F, Shakeri H, Arman F, Koushki D, et al. The effect of injuryrelated characteristics on changes in marital status after spinal cord injury. Iranian Journal of Public Health. 2015; 44(10): 1395.

33. Dorstyn D-S. Effectiveness of cognitive behaviour therapy and telecounselling for the treatment of psychological problems following spinal cord injury. [PhD Thesis]. [South Australia]: University of Adelaide, School of Psychology; 2012. Available from: http://hdl.handle.net/2440/75356

34. Schönherr MC, Groothoff JW, Mulder GA, Eisma WH. Participation and satisfaction after spinal cord injury: results of a vocational and leisure outcome study. Spinal Cord. 2005; 43(4): 241-248.
35. Kennedy P, Lude P, Taylor N. Quality of life, social participation, appraisals and coping post spinal cord injury: a review of four community samples. Spinal Cord. 2006 Feb; 44(2): 95-105.

36. Roger KS, Hatala A. Religion, spirituality \& chronic illness: A scoping review and implications for health care practitioners. Journal of Religion \& Spirituality in Social Work: Social Thought. 2018 Jan 2; 37(1): 24-44.

37. Reinhardt JD, Ballert C, Brinkhof MW, Post MW. Perceived impact of environmental barriers on participation among people living with spinal cord injury in Switzerland. Journal of Rehabilitation Medicine. 2016; 48(2): 210-218.

38. Ojoawo AO, Igudia JO, Mbada CE, Ayodele TO, Adedoyin RA. Assessment of life satisfaction among physiotherapists from selected hospitals in South-Western Nigeria. Nigerian Journal of Medical Rehabilitation. 2013; 16(2): 143-150. Available from: https://doi.org/10.34058/njmr.v16i2.8316(2). 